\title{
LUDWIG LACHMANN AS A THEORIST OF ENTREPRENEURSHIP
}

\begin{abstract}
One of the distinctive features of the Austrian School of Economics has been its emphasis on the entrepreneur as central to the market process. One 20th century Austrian whose work is normally not thought of as making a major contribution to the Austrian theory of entrepreneurship is Ludwig Lachmann. However, a careful reading of his 1956 book Capital and its Structure can tease out a theory of the function of the entrepreneur that is distinctly different from that of Israel Kirzner, yet still clearly situated in an Austrian conception of the market process. In this contribution, I want to emphasize two points that have been raised by previous work on Lachmann, but not explored in any detail. The first is that Lachmann's conception of entrepreneurship is deeply bound up with the need to engage in monetary calculation thanks to the heterogeneity of capital and uncertainty of the future. For Lachmann, the key function of the entrepreneur is to "specify" the uses of capital goods. Such specification requires the use of money prices and what Mises called monetary calculation. The second contribution is to offer more detail on the way in which entrepreneurs both creatively specify and re-specify the uses of their capital goods in response to profit and loss signals. The constant shuffling and reshuffling of capital goods, of which coming up with new products or new twists to old ones are a part, is the essence of Lachmann's implicit vision of entrepreneurship. For Lachmann, entrepreneurship is bound up with resource ownership and deployment through the creation and revision of plans in ways that are much more active than Kirzner's conception of the entrepreneur.

Keywords: Ludwig Lachmann; Entrepreneurship; Austrian School; Economic Calculation; Capital Goods
\end{abstract}

One of the distinctive features of the Austrian School of Economics has been its emphasis on the entrepreneur as central to the market process. From Carl Menger to Ludwig von Mises to Israel Kirzner, the entrepreneur has been prime mover of the market process and its ability to generate economic coordination. Entrepreneurship is bound up with the Austrian focus on disequilibrium processes and the role of economic institutions, in particular the price system, in enabling actors to better coordinate their expectations 
and actions despite the dispersed and subjective nature of human knowledge. Figuring out not just what to produce but how to produce it using the least valuable resources possible is the problem that we must solve, and it is entrepreneurs who take on that responsibility in the Austrian vision of the market economy.

One $20^{\text {th }}$ century Austrian whose work is normally not thought of as making a major contribution to the Austrian theory of entrepreneurship is Ludwig Lachmann. Lachmann is thought of primarily as a theorist of capital and of the coordinative role of institutions in a world of structural uncertainty. His radical subjectivism, however, often seemed to point to a less coordinated world that one would expect to see if entrepreneurial alertness were as widespread and powerful as it appears to be in the work of Mises and Kirzner. That fact that, as we will see, Lachmann was more skeptical that the forces of order would so clearly overcome the disruptive effects of change and uncertainty does not disqualify him from saying important and substantive things about the entrepreneurial function.

A careful reading of his 1956 book Capital and its Structure can tease out a theory of the function of the entrepreneur that is distinctly different from that of Kirzner, yet still clearly situated in an Austrian conception of the market process. Endres and Harper (2013) offer one such attempt, including not only the 1956 book but a much broader corpus of Lachmann's work. Much of what I want to argue here builds on their analysis of Lachmann's approach to entrepreneurship. In extending their work, I want to emphasize two points that they raise but do not explore in any detail. The first is that Lachmann's conception of entrepreneurship is deeply bound up with the need to engage in monetary calculation thanks to the heterogeneity of capital and uncertainty of the future. For Lachmann, the key function of the entrepreneur is to "specify" the uses of capital goods. Such specification requires the use of money prices and what Mises called monetary calculation. Lachmann underplays this point for a variety of reasons, and, in what follows, I attempt to bring it more to the forefront. In this way, Lachmann's entrepreneur seems closer to Mises's concept of the "entrepreneurpromoter" than it is to Kirzner's "alert" entrepreneur. One implication of this first point is to go beyond Endres and Harper in not just differentiating Lachmann from Kirzner, but arguing more explicitly that the Lachmannian entrepreneur is far closer to that of Mises.

The second contribution of what follows is to offer more detail on the way in which entrepreneurs both creatively specify and re-specify the uses of their capital goods in response to profit and loss signals. For reasons we will explore, Kirzner gives the entrepreneur no role beyond being alert to changes 
in the economic data that create profit opportunities. The Kirznerian entrepreneur is there to solve a particular problem in neoclassical microeconomics. In defining the role of the entrepreneur this way, Kirzner gives us a very narrow notion of entrepreneurship, which contrasts with Lachmann's (and Mises's). For example, Kirzner is explicit to say that entrepreneurship, purely considered, requires no resource ownership. By contrast, the constant shuffling and reshuffling of capital goods, of which coming up with new products or new twists to old ones are a part, is the essence of Lachmann's implicit vision of entrepreneurship. This is much more than being alert to changes in the data. For Lachmann, entrepreneurship is bound up with resource ownership and deployment through the creation and revision of plans in ways that are much more active than Kirzner's conception of the entrepreneur.

In what follows, I outline Mises's conception of the entrepreneur and its relationship to his discussion of monetary calculation. In the next section, I contrast that with Kirzner's focus on alertness. I then turn to Lachmann's work, exploring first his account of the entrepreneur as the person responsible for "specifying" how capital goods get used. This will require backtracking into Lachmann's theory of capital. In that section, I will make the case for the role of monetary calculation in Lachmann's vision. The last section looks at how this view of the entrepreneur plays out in a dynamic market process when resources owners are confronted with profits or losses. I will argue that the subsequent process of re-specifying how capital goods are used as part of the plan revision process is a crucial exercise of the entrepreneurial function that is just as, if not more, important than the original entrepreneurial insight and specification of capital goods, as Lachmann himself understood. A short conclusion follows.

\section{Mises on Monetary Calculation and the Entrepreneurial Function}

The entrepreneur has always played a central role in the Austrian tradition, starting with Carl Menger's (1985 [1871]) Principles, which founded the school. Ludwig von Mises (1966 [1949]) offered the first really comprehensive discussion of entrepreneurship in his treatise Human Action, first published in English in 1949. Mises's discussion interests us here for several reasons. First, it was the most influential on Lachmann. In addition, Mises situates entrepreneurship within the broader context of the idea of monetary calculation. That context is important not just for understanding 
entrepreneurship in general, but for seeing Lachmann's particular contribution to entrepreneurial theory in the most productive way.

The fundamental challenge of economic production involves answering the twin questions of "what should be produced?" and "how should we produce it?" The first of the two questions relates to consumer preferences: what is that people wish to buy, or might wish to buy if it were available to them? The second question, which is the one that is often overlooked especially by critics of capitalism, is the harder one: if we are to make this product, which combination of inputs should we use to make it such that we use the least valuable inputs possible? This question is what economists mean by "economic efficiency." From a social perspective, we want to be able to answer both of these questions so that we do not waste resources either making things that people do not want, or making things that they do want in ways that are unnecessarily wasteful. These two questions thus raise a further question: under what sorts of social institutions will we be best able to answer both of those questions?

Answering those questions involves determining whether our methods of production are creating value. There are many things that people might wish to have, but if we are to use resources wisely, we will only make those things where the value of the final product exceeds the total value of the inputs required to make them. If we are to transform inputs into outputs, we want to add, not destroy, value in the process. How can we know if we have succeeded or failed at adding value? The answer is that we need some way to compare the value of alternative goods and alternative processes of production to determine whether value is being added or lost, and which of those alternative processes adds the most. For Mises, this is the role of what he calls "monetary calculation."

What enables us to engage in these comparisons of value are market prices determined by the exchange of goods and service against money. As Mises (1920) argued earlier in the $20^{\text {th }}$ century, the ability to engage in those comparisons thanks to market prices is what is missing from attempts to substitute socialist planning for the capitalist market. Market economies are able to use resources rationally because they have market prices. They have market prices because they have private property, particularly in the means of production, which enables people to exchange and form markets, which in turn leads to the emergence of market prices. For Mises, and for the Austrian school more generally, the case for the market economy rests on the argument that only markets and market prices make it possible for us to compare alternative production possibilities and determine which are the more rational use of resources. Put differently, there are all kinds of pos- 
sible goods and services we might create using a large variety of production processes, but it is only the existence of market prices that lets us narrow down those possibilities to the ones that are economically efficient.

Monetary calculation is the process by which resources owners determine what they will produce and how, and then learn whether they have done so successfully or not. Market prices allow us to calculate before we engage in economic activity which choices are likely to be best. In the context of a firm producing a good or service, this involves imagining alternative production plans and creating budgets based on each. Budgets are, of necessity, speculative, both in terms of the expected costs and the expected revenues. But they do enable a first attempt at eliminating production processes that are too costly given the producer's best estimate of likely revenues. In the absence of prices and monetary calculation, producers would be completely in the dark as they attempted to choose from among alternative production plans. For example, without prices, how would producers know that, even if it were technologically possible to make some good out of platinum, it might not be the wisest choice given its cost? How would producers choose among brick, wood, or metal in deciding how to build a house?

Monetary calculation is also relevant in determining whether a particular production process did, in fact, create value. A budget uses market prices in a forward-looking way, while profit and loss tell us after the fact whether or not we made a good choice. The ability to calculate whether the choice to build the house out of wood was a wise one is only possible with market prices and the institutional conditions that make them possible. What profits mean is that the value of the final product to consumers was greater than the sum of the value they placed on the individual inputs (with due account for the passage of time via interest). Losses, by contrast, indicate that the final product was valued less highly than the sum of the inputs, suggesting that the producer should not have embarked on that particular path. Monetary calculation of profits and losses provides producers with ex post feedback about the wisdom of their past choices that, without market prices, would be unavailable.

All of this takes place, as Mises notes, in the context of uncertainty. Producers cannot know for sure what consumers want or if their production plan is the best one. It is through what F. A. Hayek (1978) would later call "the discovery procedure" of the market that we learn what it is that consumers want and how best to produce it. Monetary calculation is essential to Mises's vision of a market driven by "consumer sovereignty," understood as the idea that producers must respond to the demands of consumers and that it is those demands that determine who profits and who loses and the 
pattern of resource distribution more generally. Ultimately, who is rich and who is poor is the result of consumer preferences and how well producers and workers respond to them. Budgets, profits, and losses calculated using market prices are what link together the demands of consumers and the choices of producers: "In the absence of profit and loss the entrepreneurs would not know what the most urgent needs of the consumers are. If some entrepreneurs were to guess it, they would like the means to adjust production accordingly" (Mises 1966 [1949]: 299).

Once we recognize that this process is shrouded in uncertainty, we can begin to understand the role of the entrepreneur. The challenge is peering into an unknowable, but not unimaginable, future and trying to make the best use of current resources. Someone has to take responsibility for anticipating future needs and making the relevant decisions about resource use. One could imagine one possibility being some sort of collective decisionmaking process in which we all decide on one path forward. The problem with such a proposal is that without the opportunity to experiment in real time with alternatives, we restrict our ability to discover new and better ways of doing things. There is no way to know without actually producing whether one or another process will actually be the best decision. Leaving that in just one set of hands seems unnecessarily risky. A system in which multiple actors experiment with alternative production processes and where those actors are informed of how well their processes worked and provided with an incentive to fix them would be more likely to generate good results over time, with the risk of any particular failure being minimal. This dispersal of ownership, what Hayek called "several property" to reflect the fact that property is not just private but dispersed, enables the experiments in production that constitute entrepreneurship. With multiple actors able to try out various different options, both prior to production via the budgeting process and then in actual market competition, entrepreneurs are not only incentivized to outdo their competition, they are provided with profit and loss feedback as to how well they did.

For Mises, the entrepreneur is the "driving power in the market economy" (1966 [1949]: 299). It is the entrepreneur's task to anticipate the wants of the consumers and bring resources together in such a way as to provide them, and to do so at the least cost possible. Ultimately, it is the consumers who determine whether entrepreneurs got it right, and the indicator of consumer satisfaction is profit and loss. Profits turn control over more resources to those who were more correct in their anticipations, while losses remove resources from those who were wrong. Entrepreneurs are constantly trying to serve consumers better and better as it is the consumer who holds the power 
of riches or bankruptcy over the heads of entrepreneurs. Entrepreneurs take those risks and market prices provide the guidance they need to both peer into the future and summarize the actions of the past.

If there is a weakness in Mises's presentation of the entrepreneur, it is that he sometimes portrays the entrepreneur as somewhat passive given Mises's emphasis on consumer sovereignty. The entrepreneur's fortunes are indeed at the mercy of the choices of consumers to the extent that we focus on the revenue side. However, entrepreneurs must exercise judgment about which combination of inputs to use to produce whatever it is they think consumers want. It's certainly true that the prices of those inputs are the result of how consumers evaluate all of the various options in front of them, but that does not take away the act of judgment that is involved in making decisions about production processes. Mises (1966 [1949]: 290-1) argues that the "specific entrepreneurial function consists in determining the employment of the factors of production." As we will see in the next section, Israel Kirzner's entrepreneur is even more passive as, for Kirzner, the entrepreneur's main function is being alert to changes that have already taken place. By contrast, the implicit vision of entrepreneurship in Lachmann is a much more active one, and much closer to Mises's view.

\section{Kirzner on Entrepreneurial Alertness}

Israel Kirzner's theory of entrepreneurship was first fully elaborated in his 1973 book Competition and Entrepreneurship. That book was the key catalyst of the revival of interest in the Austrian School that began in the mid-1970s and has grown continually since then. One of the reasons the book was so important is that in elaborating a distinctly Austrian understanding of the entrepreneur, Kirzner placed his theory in the context of thencontemporary neoclassical microeconomics. The standard model of perfect competition assumed a world in which every seller was a "price taker," exercising no ability to change the price unilaterally. Sellers took the prices established by "the market" as givens. One way of understanding this is that the model also assumed a large number of very small sellers, so no single one of them could exercise any influence on the overall market outcome. Of course, when economists went to analyze the market as a whole, they still spoke of prices changing as a result of changes in supply and demand. What Kirzner essentially asked was "if every seller is taking prices as given, how exactly does the price change at the market level?" The answer within the standard model was the deus ex machina of an imagined "auctioneer" 
who would call out prices to both buyers and sellers until the equilibrium price was found. Although this device was necessary to maintain the prior assumptions about the size of firms and price-taking behavior, and to make the mathematics of the theory tractable, it was clearly problematic as a way of understanding real world markets.

Kirzner's answer to the question of "who changed price" was the entrepreneur. The only way to understand how the equilibrium of perfect competition was attained was by entrepreneurial action that saw opportunities within existing disequilibria to profit by the reorganization of production. As I have written elsewhere (Horwitz 2004), another way to see what Kirzner was doing here was as a "Misesian answer to a Hayekian question." In his 1937 essay "Economics and Knowledge," Hayek (1948 [1937]) argued that the market was a process of social learning by which the expectations of actors came into increasing coordination with each other. This "dovetailing of plans" was perfected in equilibrium when the expectations of each actor about the external world and the expectations of other actors were all correct, enabling everyone to execute their plans without disappointment. What Hayek left incompletely answered in that essay was the precise process by which those expectations and plans were brought into coordination with each other. Kirzner built on Mises's conception of the entrepreneur to explain how entrepreneurs did so.

The key for Kirzner is the distinction between what he calls "Robbinsian maximizing" and entrepreneurship. Robbinsian maximizing is named after Lord Lionel Robbins whose book An Essay on the Nature and Significance of Economic Science (Robbins 1932) defined economics as the allocation of scarce means among competing ends. That definition made economics into a static problem of maximizing the efficient allocation of resources. In particular, it took both means and ends as given and asked how best to allocate those means among those ends. As Kirzner points out, with this definition, there is no real "choice" by producers. If, for example, they are assumed to profit maximize, their point of optimal production is implied by the given data. They do not "choose" their levels of output and price, they simply "pop out" of the data they are given. This approach might be useful for computing those levels of output and prices if one is assuming that defining equilibria is the goal, but it is less useful for understanding how economies evolve and change.

Kirzner is interested how humans choose in disequilibrium and thereby drive economies toward the full coordination equilibria that Hayek discussed. In a world of disequilibrium, plans are not fully coordinated and some actors are able to recognize that discoordination and imagine ways of 
correcting it. For Kirzner, that ability to recognize opportunities for profit by correcting existing discoordination is what he calls "entrepreneurial alertness." What entrepreneurs do is shift the "given" means-ends framework by being alert to alternative uses of resources that would better satisfy consumer demands. The entrepreneur notices either shifts in consumer preferences or the costs of various resources and recognizes that either one shifts the given means-ends framework such that the optimal outcome is no longer implied by that old data. That moment of recognition is the moment of entrepreneurship for Kirzner. Once that moment has passed and a different means-ends framework is in place, action returns to Robbinsian maximizing with the new framework. The essence of entrepreneurship is that alertness to new information and understanding how to integrate it into a new picture of economic reality.

The classic example of Kirznerian entrepreneurship is pure arbitrage. If apples are selling for $\$ 2$ per pound on one side of the street and $\$ 4$ per pound on the other, the plans of buyers and sellers are discoordinated as both are missing out on opportunities to do better than they are. The person who walks down the street alert to the possibility of such discoordination is more likely to discover it and be able to exploit it. The recognition of the price differential is the moment of entrepreneurship. From there, it is a matter of maximization to execute the act of paying something more than $\$ 2$ for the pound of apples on one side and offering it for something less than $\$ 4$ on the other side of the street. The recognition, however, that the means-ends framework could be different than it was is the moment of entrepreneurial insight. Notice that it is entrepreneurship that now causes the disequilibrium prices on either side of the street to be moved closer to equilibrium. The market price changes because the entrepreneur does not take prices as given and takes advantage of the profit opportunity presented by the disequilibrium. In so doing, the entrepreneur also activates the social learning process described by Hayek: the sellers of $\$ 2$ apples learn that they can get more for their apples, and the buyers of $\$ 4$ apples learn that they can purchase them for less. Each group's mistaken expectations are corrected and brought more into coordination with each other. Entrepreneurship is the way in which expectational errors are corrected and markets are driven toward more complete coordination.

This concept of entrepreneurship is relevant even as we move away from the example of pure arbitrage. A great deal of entrepreneurial activity takes the form of transforming a set of inputs into an output that will be more highly valued. One can frame this as a form of "arbitrage over time." The person who sees a pile of wood, a saw, a hammer, and a bag of nails and 
thinks "I could take those and transform them into a ladder" is engaged in a form of intertemporal arbitrage. That is also a moment of entrepreneurial alertness that recognizes a disequilibrium in which expectations are less than fully coordinated. Assuming, in fact, that people would value a complete ladder more than the sum of the individual inputs (accounting for the passage of time in the form of interest), the entrepreneur who sees in those inputs the possibility of a ladder has had a correct entrepreneurial insight. Once the entrepreneur adjusts the means-ends framework this way, she can then execute the plan to build a ladder and discover whether her entrepreneurial insight was a good one. For Kirzner, like Mises, the role of profit and loss is to inform entrepreneurs as to whether their actions created or destroyed value.

The importance of Kirzner's contribution was enormous, both in terms of its long-term effect on enhancing the role of the entrepreneur in economics and for laying out a path for the revival of the Austrian school in particular. However, Kirzner's theory of the entrepreneur was designed to tackle a very specific question ("if everyone takes price as given, how does the market price ever change?") with a very precise answer ("by alertness to arbitrage opportunities in disequilibrium"). What it does not give us is anything like a full-fledged theory of the firm and the entrepreneur's role within it. Very much in the spirit of Mises, Kirzner is emphasizing entrepreneurship as an element of all human action in the form of that alertness to new opportunities and re-imagining the means-ends framework. We all do that in all the aspects of our lives, and not just in the form of more narrowly "economic" activity. For example, we are entrepreneurial when we realize there is a shorter way to get to that new restaurant we like. As both Mises and Kirzner argue, this element of human action is central to understanding the market process. But it does not tell us nearly enough about how actual firms operate and how they respond to the ongoing evolution of the markets in which they operate.

Kirzner is explicit in arguing that entrepreneurship requires no resource ownership. As discussed earlier, the entrepreneurial moment is the recognition that the means-ends framework has changed. What happens after that is no longer, strictly speaking, entrepreneurship but management subject to Robbinsian maximizing processes. Our apple arbitrageur requires no resources to recognize the opportunity for profit that the street presents him. Once he sees that, it is a matter of optimizing behavior given the new means-ends framework. In the context of pure arbitrage, even that step in the process requires no resources, as in the most extreme case, the entrepreneur could borrow the funds to purchase the apples and pay that loan 
off with the profits. When we compare the case of production through time, here too, a loan could be used to purchase the relevant inputs. However, someone has to decide which inputs to purchase and how exactly to deploy them. And, more important, someone has to decide, after a firm's profits or losses are known how to revise plans and proceed in the next round. For Mises, this work is that of the entrepreneur "determining the employment of the factors of production." Although Kirzner's concept of entrepreneurship solves a very important puzzle facing standard economic theory, it is less clear how useful it is for describing the way firms, especially understood as collections of ownership rights over inputs, behave in real-world markets. Mises's broader conception of the entrepreneur as exercising control over the employment of the factors of production seems more suited to this task, particularly when combined with Mises's emphasis on the importance of monetary calculation in that process. What would help flesh out Mises's conception of the entrepreneur is more detail on what is involved with "employing the factors of production." It is there that the work of Ludwig Lachman is most helpful.

\section{Entrepreneurship, the Firm, and the Specification of Capital Goods}

Ludwig Lachmann wrote very little on entrepreneurship specifically. His implicit theory of entrepreneurship can be teased out of his work on capital theory, especially in his 1956 book Capital and its Structure. Lachmann's task in that book is to explore the problems of "the order of capital." He wants to explain how the particular constellation of capital goods comes into being and changes as economic processes unfold. At the center of his work on capital is the idea of capital heterogeneity. Almost every capital good can be used for some number of purposes that is greater than one but less than infinity. Capital goods have "multiple specificity." That is, they can be used for some finite number of purposes, with varying degrees of productivity in each. One implication of this claim is that if we wish to move a capital good from one use to another, there are likely to be "re-fitting" costs. Even if capital has multiple uses, not all of them can be engaged by the capital in its precise current condition. This heterogeneity in use applies both to individual capital goods and to the whole range of goods that constitutes the stock of capital. Any single good has multiple, though not infinite uses, and the possible uses of all of the capital goods in the economy overlap in a variety of ways. 
As Mises also observes, were it the case that capital goods had one and only one use, the structure of capital would not present much of an explanatory problem, as there would be no decision about how to allocate particular pieces of capital. Similarly, if all capital goods could be used for any purpose, explaining the structure of capital would be far less complicated, given that it would just be a matter of how much of some aggregate of capital needed to be applied to produce whatever it is that consumers wanted. ${ }^{2}$ The challenge posed by capital in the real world is that any particular output can normally be produced with a variety of combinations of inputs, while any given input can be used to help produce a variety of different outputs. Owners of capital goods must decide what they wish to produce and which combination of capital goods will be the appropriate one to accomplish that goal.

Lachmann (1978 [1956]: 8) puts the concept of "the plan" at the center of his theory of capital: "Capital uses must 'fit into each other.' Each capital good has a function which forms part of a plan." He (1978 [1956]: 35, emphasis in original) later expands these comments: "The theory of capital must therefore concern itself with the way in which entrepreneurs form combinations of heterogeneous capital resources in their plans, and the way in which they regroup them when they revise these plans." This sentence contains the essence of Lachmann's theory of capital and the role played in it by the entrepreneur. Production requires a plan based on combinations of capital goods and what it means to be an entrepreneur is to take responsibility for creating and revising those capital combinations and to have the rights to use the capital goods that comprise them.

Beyond making decisions about the use of existing capital goods, the entrepreneur must also "specify and make decisions on the concrete form the capital resources shall have" (1978 [1956]: 16). In this way, it is the entrepreneur who is responsible for creating (in an economic, if not a physical, sense) at least some of his capital goods and thereby endowing them with the specific qualities that they require according to his vision of the production plan. Through their various contractual arrangements, the owners of those capital goods have "delegated the power of specification to the entrepreneur," making those owners bearers of significant uncertainty (Lachmann 1978 [1956]: 17). If the entrepreneur is wrong about the benefits of the particular specification he has given to those capital goods, some of the losses will be born by the owners not just the entrepreneur. Recall that refitting a capital good for a new use is costly, and it is the owners who will bear those costs if the entrepreneur's overarching plan fails. 
In constructing this production plan and the specification of capital goods that it requires, the entrepreneur must be concerned with the complementarity of those goods. What it means to create a production plan is to bring together a collection of capital goods that "fit into each other" such that they are believed to be capable of producing the desired output at the least cost. That notion of "fit" is what Lachmann means by the "complementarity" of capital goods. As he notes, complementarity is a feature of the static world embodied in the plan. It is a property of the capital goods in the snapshot of the plan at the beginning of the period of its execution. Lachmann (1977 [1947]: 200, emphasis in original) says of complementarity:

All the means jointly employed for the same end, or such ends, are necessarily complements. Factor complementarity presupposes a plan within the framework of which each factor has a function. It is therefore only with respect to a given plan that we can speak of factor complementarity.

In addition, complementarity is based on the perception of the entrepreneur who has formulated the plan. Lachmann (1978 [1956]: 3) puts it this way:

The "best" mode of complementarity is not a "datum." It is no way "given" to the entrepreneur who, on the contrary, as a rule has to spend a good deal of time and effort in finding out what it is. Even where he succeeds quickly, he will not enjoy his achievement for long, as sooner or later circumstances will begin to change again.

Lachmann (1978 [1956]: 54) later calls this "plan complementarity" to distinguish it from the "structural complementarity" of the entire capital structure. As he notes, the former is "brought about directly by entrepreneurial action" while the latter happens, if at all, "indirectly, by the market, viz. by the interplay of mostly inconsistent entrepreneurial plans."

Entrepreneurs formulate production plans based on their perception of the complementarity of the inputs for the purposes of producing the desired output. From each of their perspectives, they have created the "optimal" production plan. Each individual plan is internally consistent. The problem is whether or not each of their plans is consistent with each other. If two entrepreneurs both plan to use the same resources as part of their production process, only one will succeed. It is in the interaction of these plans in the market that we discover whether or not, and to what degree, those original plans were the best use of resources from a broader social perspective. Lachmann (1978 [1956]: 23) says of the businessman's expectations that he "is doing precisely what a scientist does when he formulates 
a working hypothesis." Those expectations are embodied in the complementarity of the production plan and it is only through testing that "hypothesis" on the market that entrepreneurs find out if their expectations and plans are correct. As each of them adjusts to the results of that market test (about which more in the next section), they reformulate those plans, and they may well generate the indirect structural complementarity of the entire capital structure. Should each and every entrepreneur's production plan become executable as is (i.e., both internally consistent and consistent with the other entrepreneurs' plans), then the overall structure of capital will be complementary. Of course in a dynamic world with everchanging data, perfect structural complementarity will never emerge, but like other equilibrium constructs, it is useful as a foil for the dynamic change of the real world.

Lachmann's argument here again recalls Hayek's (1937) "Economics and Knowledge" paper noted earlier. Hayek frames his argument there as about the distinction between individual equilibrium and overall equilibrium. Hayek's individual equilibrium is coordinated by the subjective evaluations of the actor. In this way, it is the analogue of Lachmann's "plan." Actors examine the resources at their disposal and construct a plan of consumption or production based on their perceptions of the value of various resources either in terms of utility or potential profitability. They are assisted in this process by market prices, but the ultimate evaluation is according to the judgment of the actor. It is her perceptions that integrate the elements into a plan or bring the pieces into equilibrium relationships with each other. By contrast, overall economic equilibrium happens for Hayek when all the plans of those individuals dovetail such that they can all be successfully executed. Specifically, those individual plans must contain correct expectations of both the objective facts of the world and the plans, and therefore the subjective expectations, of other actors. Hayek's overall equilibrium corresponds to what Lachmann calls the structural complementarity of the overall order of capital.

The key question for both thinkers is how one gets from individual plans that likely conflict to a world in which those plans are increasingly coordinated. That is, how do we get from individual equilibria that are in overall disequilibrium to overall equilibrium? For Hayek, as for Lachmann, the market is the process by which individuals learn of the success and failure of their plans and adjust those plans in ways that promote greater plan coordination. In particular, it is through changes in prices, and the changes in profits and losses that they induce, that actors learn about the success of their plans and the consistency of those plans with the plans of 
other actors. Those market process drive economies to overall equilibrium from the original disequilibrium of individuals' subjective perceptions, and they induce the emergence of the structural complementary of the capital structure out of the subjectively complementary but objectively conflicting plans of entrepreneurs.

It is here where the Misesian flavor of Lachmann's implicit theory of entrepreneurship comes to the surface. Although Lachmann does not pay almost any attention to it in an explicit way, one central aspect of his theory of entrepreneurship is the monetary calculation that is at the heart of Mises's work. In creating the complementary structure of capital that is the core of his production plan, the entrepreneur must engage in the cycle of budgeting, producing, and plan reformulation based on profit and loss. This cycle requires the use of money prices and monetary calculation. In deciding which among the multitude of possible combinations of inputs he will use for this particular production process, the entrepreneur has to, as Mises made clear, have recourse to market prices. Those alternative plans can then be turned into a budget for the production process. Along with the entrepreneur's best estimates of revenues, themselves requiring market prices reckoned in money, those alternative budgets allow the entrepreneur to decide which plans look the most profitable. The core problem in economics is how to choose from among the various technologically possible production possibilities, the one that is economically the most efficient. What the Lachmannian entrepreneur does in creating a production plan characterized by capital complementarity is to engage in precisely this task. ${ }^{3}$

Money prices and monetary calculation enable the entrepreneur to specify the precise combination of capital goods that is the most economically efficient for the production of the output in question. Entrepreneurship certainly includes being alert to opportunities to remove ignorance by seeing what others have not seen. But that moment of Kirznerian insight is only the beginning of a process that includes a great deal of judgment about what exactly needs to be produced and the best way of doing it. It is not clear that once the means-ends framework has shifted thanks to the moment of alertness that the rest of the entrepreneur's job is a fairly static maximization problem. Unless one builds into "alertness" the entire process by which the entrepreneur constructs the production plan from start to finish, there remain elements of entrepreneurial judgment throughout the process. The uncertainty of future prices, for both the inputs and the output, demands that the entrepreneur exercise some judgment about which combination of inputs is best. More important, the complementarity of inputs is not inher- 
ent in the goods themselves, but rather a subjective perception of the entrepreneur. What constitutes an appropriately complementary set of capital goods is not something that can obviously be construed as a maximization problem.

These points become more clear when we recall the centrality of expectations to Lachmann's theory of capital. He (1978 [1956]: 20-21, emphasis in original) writes: "Expectations, on the other hand, always embody problematical experience, i.e. an experience that requires interpretation... There is a subjective element in the acts of the mind by which we select those portions of our experience we allow to affect our judgment of the future." Formulating a budget and production plan based on the complementarity of the inputs into that plan is not possible without the exercise of entrepreneurial expectations that make use of monetary calculation. Those expectations necessarily rest on the subjective interpretations of those entrepreneurs, rendering highly suspect the Kirznerian story of a moment of alertness followed by Robbinsian maximization. As an explanation of how prices ever change, Kirzner's theory of entrepreneurship is successful. However, it does not offer full-blown theory of the process from the moment of alertness to the production of an output and the subsequent profit and loss feedback and plan revision.

Integrating Lachmann's work on capital with Mises on monetary calculation enables us to sketch out a more complete theory of entrepreneurship than we find in Kirzner. We can see those differences even more clearly when we continue the story beyond just the initial specification of the capital goods and production plan. Lachmann's theory of capital has a more fully dynamic element to it that gives the entrepreneur an essential and active role in responding to the results of executing that original production plan. In the final section, I explore Lachmann's discussion of the "substitutability" of capital, emphasizing the way in which entrepreneurs must "re-specify" capital goods and re-conceptualize their production plan by interpreting the profit and loss data of the market.

\section{The Re-specification of Capital as an Entrepreneurial Function}

In the discussion so far, I have emphasized what Lachmann calls the complementarity of capital as entrepreneurs create a production plan. The complementarity of capital, including human capital, is what enables entrepreneurs to form what they perceive as coherent production plans. 
In that sense, complementarity is a feature of the static world of the individual equilibrium of plan formation. However, as we have noted, unless all of those individual plans completely and perfectly dovetail, putting us in economy-wide equilibrium, some, if not many, of them are destined to fail. Entrepreneurs discover the success or failure of their plans via the profit and loss signals of the market. Faced with losses, or perhaps with profits less than expected, they will have to decide how to respond. A significant part of that response will be re-thinking the production plan that produced the disappointing results. Re-thinking that plan will involve a reconsideration of the capital that was used to create it.

Faced with the need for change created by profit and loss signals, entrepreneurs must shift their focus from the complementarity of capital to its substitutability. With their plans having failed, at least to some degree, entrepreneurs will have to decide what needs changing as they move forward. The question will be the degree to which alternative capital goods and human capital can be substituted for those in the previous plan. Consider a restaurant owner accumulating losses. Did she not have enough staff? Too many? Not the right proportions between front of the house and back of the house? Were her ingredients not fresh enough? Were the table settings not right? Should she have offered takeout? There are dozens of this sort of question that need to be answered and whatever the answers are, they will almost certainly require the substitution of new capital goods and human capital for the old. As Lachmann (1977 [1947]: 200) put it: "Factors are complements insofar as they fit into a production plan and participate in a productive process. Substitution, on the other hand, is a phenomenon of change the need for which arises whenever something has gone wrong with a prior plan."

So one of the features of capital goods we have to consider is their degree of substitutability for other capital goods. We can define a factor's "substitutability" as "the ease with which [it] can be turned into an element of an existing plan" (Lachmann 1977 [1947]: 200). The entrepreneur deciding what changes in her production plan are required for the next period will have to consider the degree to which particular capital goods are sufficiently versatile, to use Lachmann's word, to be integrated into the larger scale plan she is attempting to execute (e.g., running a profitable restaurant). This notion of versatility is but another way of looking at a capital good's degree of specificity. More versatile goods are less specific, while those with less versatility are more specific. When Lachmann, and other Austrian economists, speak of the "multiple specificity" of capital, they are referring to the degree of its versatility. 
To use our language from earlier, profit and loss signals force entrepreneurs to "re-specify" capital goods in the process of revising their production plan. Goods with sufficient versatility to be integrated into a revised production plan will have to have their particular use specified for that particular combination of resources. This is a "re-specification" because the good was presumably being used in some other production plan, or perhaps lying idle, either of which requires adjustments for its role in a new plan. One can think of the way in which new employees have to be trained for a new job or new responsibilities, or that a computer might need new software when purchased for a new business, as examples of re-specification. These goods and human capital could be already employed by the firm in question or might be purchased from the outside. In either case, the key question will be the degree to which those new inputs can be substituted for ones in the version of the plan that is under revision.

It is worth emphasizing that all of this activity of the entrepreneur is necessitated by the unexpected change that characterizes the world we inhabit. In a world where the future is unknowable but not unimaginable, every production plan is nothing more than a hope. The clash of those plans in the market will produce outcomes that no one could have anticipated, and this, in turn, means that numerous plans will not match the expectations of their creators. Lachmann (1978 [1956: 13) notes that this context is what gives meaning to entrepreneurship:

We are living in a world of unexpected change; hence capital combinations, and with them the capital structure, will be ever changing, will be dissolved and re-formed. In this activity we find the real function of the entrepreneur.

Or, as he (1977 [1947]: 212) said elsewhere, echoing Mises: "The revision of plans is the function of the entrepreneur, the carrying out of existing plans is the function of the manager." For Lachmann, the core of entrepreneurship is not just being alert to opportunities and then formulating a production plan comprised of complementary capital. It is at least as much the ability to "dissolve and re-form" capital combinations in response to profit and loss and to do so in the face of an uncertain future. It is this specification and re-specification of capital goods as part of the revision of a plan that defines the real function of entrepreneurs.

One particular asset plays an important role in this process, and that is the firm's cash holdings. In Lachmann's (1978 [1956: 87) capital theory, "Money is an asset but it is not a capital good like other elements of a production plan." Later he refers to money as "capital good by proxy" (87). What he means there is that the entrepreneur holds a cash balance as part 
of the production plan at its outset, recognizing that the cash will be necessary to purchase various capital goods at particular moments as the plan unfolds. Because those goods cannot be purchased at the outset and stored, we build holdings of cash balances into the plan as a surrogate for the capital goods or labor services they will eventually procure. This use of cash balances is what Lachman (90) refers to as a "second-line asset." First-line assets are the actual capital goods that go into the production plan from the very start. Second-line assets are assets that the entrepreneur plans to use at later points in the production process, such as spare parts or cash for wage payments. What is key to this use of money is that it is part of the planned expenditures associated with production. It is there because some expenditures cannot be made at the outset of the production process, therefore requiring that we hold cash in the meantime.

What Lachmann calls "reserve assets" are those assets "of which it is hoped that if all goes well they will not have to be thrown in at all" (90). Reserve assets, especially cash, are distinct from second-line assets in that they do not have a planned use, but are there in case unpredictable events come to pass that require their use. One can think of a company that has a back-up machine, just in case there is some unpredictable catastrophic failure of the working version. Unlike the predictable wearing out of parts that require spares, this is more like a form of insurance against an uncertain future. But note the specificity (i.e., lack of versatility) of this reserve asset - it can only replace one specific input. By comparison, a cash reserve has near complete versatility in its ability to purchase other assets in the face of some unexpected event. Firms hold cash, on Lachmann's view, to be available for conversion to capital goods or labor services as timing requires and to be available as a kind of completely versatile capital surrogate that can be transformed into specific goods or labor services if the unexpected occurs.

This matters because it helps to understand why changes in the firm's cash balance are an indicator of success or failure. As Lachmann (90) notes: "Success means that the reserves did not have to be thrown in, extreme failure means the complete exhaustion of the reserves." What it means to experience losses is to see that cash reserve dwindling as either revenues did not achieve their expected level in the plan, or costs exceeded theirs, or both. Any of these outcomes represent plan failure, and that failure is clearly indicated in the change in cash balances we associate with losses. Profits, of course, will be reflected in an increase in those cash balances as either the plan goes more or less as expected or better than expected. This point about cash reserves also makes clear the importance of monetary 
calculation in any understanding of entrepreneurship. That market prices are reckoned in the same monetary terms as the cash reserve and profits and losses is what integrates the ability to budget for a plan, execute it, learn of its success or failure, and then revise it accordingly. Entrepreneurs cannot do their job without money prices and that whole process of monetary calculation.

These changes in cash balances (and other reserve assets perhaps) reflect the sense in which profits and losses are residuals. They are what is left after revenues are earned and costs are paid. The owners of firms are frequently referred to as residual claimants as it is they who get to keep the profits or take responsibility for the losses. In this way, the right to specify and re-specify capital goods and human capital along with the right to keep the proceeds, or the obligation to bear the losses, of the production processes associated with those inputs are what define the boundaries of the firm. Issues of ownership and firm boundaries are tied up with just these questions. The entrepreneur, and firms more generally, are those who able to decide which combination of inputs will comprise the production plan, keep the profits or bear the losses that result, and then have the right to alter that plan for the next period. The firm is the unit within which plans are constructed, evaluated, and revised: "It is now clear why factors jointly employed in the same firm tend to be complementary: they are all means to the same end, elements of the same plan. Unity of management here ensures consistency of action" (Lachmann 1977 [1947]: 201-2). Lachmann's theory of capital not only helps us to understand what entrepreneurs do, it gives us an implicit theory of the firm.

\section{Conclusion}

Given the connections among entrepreneurship, capital goods, and the firm, it is no surprise that we find a theory of entrepreneurship and perhaps a nascent theory of the firm within Lachmann's theory of capital. Lachmann's view of the entrepreneur as an active specifier and re-specifier of the uses of capital goods (and human capital) in the context of production plans that get revised using profit and loss signals puts him closer to Mises's conception of the entrepreneur than Kirzner's more narrow one. As Austrian school economists continue to sort out exactly what the role of the entrepreneur is and how it fits within economic theory more broadly, they should not neglect Lachmann's work in that endeavor. Though explicitly about capital, Lachmann's Capital and its Structure, and his related 
articles, offer a theory of the entrepreneur that is rich with empirical applications and connections to the theory of the firm that have only begun to be explored.

\section{N O T E S}

1 Of course, Mises (1966 [1949]: 291) is quick to add: "But he cannot evade the law of the market. He can succeed only by best serving the consumers. His profit depends on the approval of the consumers."

2 This, of course, is essentially Frank Knight's theory of capital. See Hayek's (1936) Austrian response.

3 Space does not permit me to explore this point in any detail, but virtually everything said about the relationship between the entrepreneur and capital inputs is true of labor as well. The fact that workers cannot be owned and can only sell their labor services is the most important difference, of course. However, that point does not matter all that much in understanding how entrepreneurs specify inputs and make use of resource complementarity to construct a production plan.

\section{R E F E R E N C E S}

Endres, Anthony and David Harper. 2013. "'Wresting Meaning from the Market': A Reassessment of Ludwig Lachmann's Entrepreneur," Journal of Institutional Economics 9: 303-28.

Hayek, F. A. 1936. "The Mythology of Capital," Quarterly Journal of Economics 50 (2): $199-228$.

Hayek, F. A. 1937. "Economics and Knowledge," in Individualism and Economic Order, Chicago: The University of Chicago Press, 1948: 33-56.

Hayek, F. A. 1978. "Competition as a Discovery Procedure," in New Studies in Politics, Philosophy, Economics and the History of Ideas, Chicago: University of Chicago Press.

Horwitz, Steven. 2004. "Monetary Calculation and the Unintended Extended Order: The Misesian Microfoundations of the Hayekian Great Society," Review of Austrian Economics 17: 307-21.

Kirzner, Israel. 1973. Competition and Entrepreneurship, Chicago: University of Chicago Press.

Lachmann, Ludwig M. 1977 [1947]. "Complementarity and Substitution in the Theory of Capital," reprinted in Walter Grinder, ed., Capital, Expectations, and the Market Process, Kansas City: Sheed Andrews and McMeel, 1977.

Lachmann, Ludwig M. 1978 [1956]. Capital and Its Structure, Kansas City: Sheed Andrews and McMeel.

Menger, Carl. 1981 [1871]. Principles of Economics, New York: New York University Press. 
Mises, Ludwig von. 1920. "Economic Calculation in the Socialist Commonwealth," in Collectivist Economic Planning, F. A. Hayek, ed., Clifton, NJ: Augustus M. Kelley, 1935.

Mises, Ludwig von. 1966 [1949]. Human Action: A Treatise on Economics, Chicago: Henry Regnery.

Robbins, Lionel. 1932. An Essay on the Nature and Significance of Economic Science, London: MacMillan. 